\title{
Analysis on Influential Factors for Anti-Infection Efficacy of Fluoroquinolones
}

\author{
Nan Wang ${ }^{1}$, Liqin Zhu ${ }^{2 *}$, Xuequn Zhao ${ }^{3}$, Ying Yang ${ }^{3}$ \\ ${ }^{1}$ Pharmacy Department, Tianjin Third Central Hospital, Tianjin, China; ${ }^{2}$ Pharmacy Department, Tianjin First Center Hospital, Tianjin, \\ China; ${ }^{3}$ Infectious Disease Department, Tianjin First Center Hospital, Tianjin, China. \\ Email: ${ }^{*}$ zlq0713@yahoo.com.cn
}

Received November $12^{\text {th }}, 2013$; revised December $25^{\text {th }}, 2013$; accepted January $15^{\text {th }}, 2014$

Copyright (C) 2014 Nan Wang et al. This is an open access article distributed under the Creative Commons Attribution License, which permits unrestricted use, distribution, and reproduction in any medium, provided the original work is properly cited. In accordance of the Creative Commons Attribution License all Copyrights (C) 2014 are reserved for SCIRP and the owner of the intellectual property Nan Wang et al. All Copyright (C) 2014 are guarded by law and by SCIRP as a guardian.

\section{ABSTRACT}

Objective: To investigate factors contributed to anti-infection efficacy of fluoroquinolones (FQNS), and ultimately to provide guidelines for the application of such drugs. Methods: Clinical data of $\mathbf{5 1 9}$ infected patients who were treated with fluoroquinolones were analyzed retrospectively. According to the therapeutic efficacy of the drugs, cases were divided into 3 groups: clinical inefficient, improved and cured. 11 potential factors were investigated. The data were analyzed through logistic regression analysis to determine the main factors which influence therapeutic effects. Results: Ordinal logistic regression revealed that age $(\mathrm{OR}=0.979,95 \%$ CI: 0.969, 0.989 ), a variety of medicine (moxifloxacin - OR $=3.465,95 \%$ CI: 1.396, 8.601; levofloxacin - OR $=4.605,95 \%$ CI: 1.971, 10.760; ciprofloxacin - OR $=3.220,95 \%$ CI: 1.089, 9.552; compared to lomefloxacin) (levofloxacin $\mathrm{OR}=2.591,95 \% \mathrm{CI}: 1.130,5.944$; compared to fleroxacin) and site of infection (respiratory system - OR = 3.016, 95\% CI: 1.737, 5.236; urological system - OR $=4.077,95 \%$ CI: 1.981, 8.391; digestive system - OR $=3.740,95 \%$ CI: 1.849, 7.565) are main factors which influence the efficacy. Conclusion: Fluoroquinolones are more effective in the treatment of bacterial infection within drug's indications in young population. Variety, dosage and intervals of the drugs should be adjusted according to disease condition.

\section{KEYWORDS}

Fluoroquinolones (FQNS); Antibiotics; Influential Factors; Ordinal Regression

\section{Introduction}

Since the first quinolone, nalidixic acid, was released for treatment of urinary tract infection as a new class of antibiotic agents in 1962 [1], it has been almost half century. About 3 decades ago, modification of nalidixic acid structure led to the synthesis of the first fluoroquinolone, norfloxacin, which presented higher activity for Gramnegative organisms and fluoroquinolones (FQNS) and also has been proved to exhibit a broader antimicrobial spectrum and relatively few side effects [2-4]. Fluoroquinolones have been commonly used in adults for the treatment of a wide range of infections. However, after the widespread but indiscriminate use of fluoroquinolones, bacterial with resistance and decreased suscep-

\footnotetext{
${ }^{*}$ Corresponding author.
}

tibility to fluoroquinolones have been increasingly reported in recent years [5-8].

During recent years, more and more excellent work has been mainly devoted to the synthesis and activitystudy of new fluoroquinolones, thus revealing the mechanism of drug resistance, etc. [9-11]. In this paper, we aimed to find how to properly and reasonably apply fluoroquinolones to reduce drug resistance. Therefore, we adopted regression analysis to identify the dominant factors which influence the result of treatment.

519 patients were involved in this study. All the patients were treated with fluoroquinolones, but with different ends. We may ask: how it happened, that was, we had to find out the influential factors hidden behind this phenomenon in order to have a properly use of them. Thus, potential factors including age, gender, duration of 
anti-infection treatment, a variety of medicine, site of infection, smoking history, alcohol history, $\mathrm{Cr}$ (creatinine) value, BUN (blood urea nitrogen) value, ALT (glutamicpyruvic transaminase) value, and AST (glutamic-oxalacetic transaminase) value, were studied through regression analysis.

\section{Subjects}

\subsection{Subjects Origin}

Cases that were treated with fluoroquinolones after diagnosed as infectious disease and within the indication of fluoroquinolones from January 2008 to April 2011 in First Center Hospital, Tianjin, China, were sorted by case numbers. The first case of every five consecutive ones was chosen in this research. After strict screening through the inclusion and exclusion criteria, 519 cases were finally selected in this study.

\subsection{Inclusion Criteria}

The inclusion criteria for the study were: 1) the patients were diagnosed as infectious disease which should be the indications of FQNS; 2) FQNS were used as monotherapy; 3 ) course of treatment were between 3 and 14 days; 4) all of the indexes for each patient were completely recorded during the course of therapy.

\subsection{Exclusion Criteria}

The exclusion criteria for the study were: 1) the patients whose data were incomplete; 2) anti-infection treatment with FQNS was ended for non therapeutic reason; 3) patients underwent surgical intervention during anti-infection treatment.

\section{Methods}

\subsection{Clinical Data Collection}

The clinical data of 519 patients who were diagnosed as infectious disease and were treated with FQNS were analyzed retrospectively. FQNS were prescribed empirically or on the basis of culture and sensitivity results in these cases. All the cases were from 8 departments, which included Respiration Dept., Urology Dept., Digestion, Combined Chinese and Western Medicine Dept., Burn and Plastic Surgery Dept., Immunology Dept., Cardiology Dept., International Medical Center, in Tianjin First Center Hospital in China and five kinds of fluoroquinolones were inclusive and analyzed.

To assess the possible influential factors of efficacy during drug therapy, different indexes were considered in the research. The demographic characters, namely age, gender, site of infection, smoking history, alcohol history were obtained from medical records. Therapeutic infor- mation, duration of anti-infection treatment, and medications, were obtained through prescription. Information on $\mathrm{Cr}$ value, BUN value, ALT value, AST value was collected according to assay sheet, which recorded the results of biochemical assay results.

\subsection{The Evaluation Criterion of Therapeutic Effect}

The therapeutic efficacy was classified into 3 grades: cured, improved and inefficient according to Guidelines for Clinical Trial of Antibacterials issued by Clinical Pharmacological Center for Antibacterials affiliated to Chinese Ministry of Health. The efficacy changes were judged by 3 aspects: 1) symptoms; 2) signs; 3) laboratory tests (blood routine test, urine routine test). All the 3 aspects returned to be normal were considered as clinical cured. If only one or two of them returned to be normal, the efficacy would be regarded as improved. If few index improved, even aggravated, it is deemed clinically inefficient [12]. When evaluating the efficacy, all the 3 aspects should be considered totally.

\subsection{Statistical Analysis}

The analysis was performed on software SPSS version 15.0. Numerical variables were expressed as mean \pm S.D. Descriptive statistics such as means and proportions were presented. One-Way ANOVA were performed to compare means of numerical variables, and the differences of ordinal data were tested using $\chi^{2}$ test. Significant level of the above statistical analysis was set as $\alpha=0.05$, and $\mathrm{P}<$ 0.05 (two-tailed) was considered as statistically significant.

Bivariate correlation analysis was conducted to assess the correlation between potential factors, which would help explain the result of regression analysis. Correlation was significant at the 0.01 level.

Efficacy of fluoroquinolones could be considered as ordinal categorical variables with more than two orderly grades. Therefore, ordinal regression was conducted in this study to determine the influential factors. Here, OR indicated the odds ratio for dependent variable to elevate one or more levels, in response to the independent variable changing for every one unit. $\mathrm{P}$ value $<0.05$ was considered significant for the analysis.

\section{Results}

\subsection{Subjects' General Information}

According to the inclusion and exclusion criteria mentioned above, a total of 519 cases were involved in this analysis. All the patients were diagnosed with infective disease, most of which was respiratory infection $(45.5 \%$, $\mathrm{n}=236$ ), and their clinical information were complete. 
As the results showed, $290(55.9 \%)$ subjects were males and the other 229 (44.1\%) were females. Mean age was $59.0 \pm 19.6$ years (range $18-91$ years). The majority of the patients were treated with levofloxacin $(49.3 \%, \mathrm{n}=$ 256). Variety of medicine, duration of anti-infection treatment, site of infection, and other information, see Table 1.

\subsection{Comparisons of Clinical Parameters}

Descriptive data of each efficacy level were displayed in Table 2. There were major differences in mean age, mean $\mathrm{Cr}$ value, mean BUN value among the three groups. The $\mathrm{P}$ values of these indexes were less than 0.05 . The mean age for patients in each of these groups were 58.6, 61.6, and 53.9 years. The mean $\mathrm{Cr}$ value was 73.7, 78.8 and 70.9 , while the mean BUN value of each group was 5.5, 5.5 and 4.8. The result of bivariate correlation analysis (see Table 3 ) demonstrated age was closely correlated with $\mathrm{Cr}$ and $\mathrm{BUN}$ value. This could be observed in the mean value of age, $\mathrm{Cr}$ and $\mathrm{BUN}$ value. Patients cured were the youngest, who, in mean while, got the lowest renal index.

In addition, significant differences were observed in both variety of medicine and site of infection among the three groups $(\mathrm{P}<0.001)$. Still, the two factors were statistically associated with each other. This trend was

Table 1. Cases general information.

\begin{tabular}{|c|c|c|c|}
\hline & Items & $\mathrm{N}$ & Percentage $(\%)$ \\
\hline \multirow[t]{7}{*}{ Departments } & Respiration Dept. & 157 & 30.3 \\
\hline & Urology Dept. & 85 & 16.4 \\
\hline & Digestion Dept. & 74 & 14.3 \\
\hline & Combined Chinese and Western Medicine Dept. & 66 & 12.7 \\
\hline & Immunology Dept. & 37 & 7.1 \\
\hline & Cardiology Dept. & 22 & 4.2 \\
\hline & International Medical Center & 18 & 3.5 \\
\hline \multirow{6}{*}{ Duration of Anti-Infection Treatment } & Inefficient & 170 & 38.2 \\
\hline & Improved & 239 & 46.1 \\
\hline & Recovered & 110 & 21.2 \\
\hline & $\leq 3$ & 96 & 18.5 \\
\hline & $4-7$ & 274 & 52.8 \\
\hline & $8+$ & 149 & 28.7 \\
\hline \multirow[t]{5}{*}{ Sort of Medicine } & Moxifloxacin & 146 & 28.1 \\
\hline & Levofloxacin & 256 & 49.3 \\
\hline & Ciprofloxacin & 40 & 7.7 \\
\hline & Fleroxacin (FLX) & 25 & 4.8 \\
\hline & Lomefloxacin & 52 & 10.0 \\
\hline \multirow[t]{4}{*}{ Site of Infection } & Respiratory System Infection & 236 & 45.5 \\
\hline & Urological System Infection & 80 & 15.4 \\
\hline & Other Infection & 75 & 14.5 \\
\hline & Mixed Infection & 70 & 13.5 \\
\hline \multirow[t]{2}{*}{ Gender } & Male & 290 & 55.9 \\
\hline & Female & 229 & 44.1 \\
\hline \multirow[t]{2}{*}{ History of Smoking } & No & 439 & 84.6 \\
\hline & Yes & 80 & 15.4 \\
\hline \multirow[t]{2}{*}{ History of Drinking } & No & 489 & 94.2 \\
\hline & Yes & 30 & 5.8 \\
\hline
\end{tabular}


Table 2. Characteristics of study population.

\begin{tabular}{|c|c|c|c|c|c|}
\hline \multirow[b]{2}{*}{ Variables } & \multicolumn{3}{|c|}{ Efficacy } & \multirow[b]{2}{*}{ Total $(\mathrm{n}=525)$} & \multirow[b]{2}{*}{$P$ value } \\
\hline & $\begin{array}{l}\text { Inefficient } \\
(\mathrm{n}=201)\end{array}$ & $\begin{array}{l}\text { Improved } \\
(\mathrm{n}=225)\end{array}$ & $\begin{array}{c}\text { Cured } \\
(\mathrm{n}=99)\end{array}$ & & \\
\hline Age, yr & $58.6 \pm 19.8$ & $61.6 \pm 19.5$ & $53.9 \pm 18.8$ & $59.0 \pm 19.6$ & 0.003 \\
\hline $\mathrm{Cr}, \mu \mathrm{mol} \cdot \mathrm{L}^{-1}$ & $73.7 \pm 24.8$ & $78.8 \pm 26.8$ & $70.9 \pm 20.5$ & $75.5 \pm 25.1$ & 0.013 \\
\hline $\mathrm{BUN}, \mathrm{mmol} \cdot \mathrm{L}^{-1}$ & $5.5 \pm 2.4$ & $5.5 \pm 2.5$ & $4.8 \pm 2.0$ & $5.4 \pm 2.4$ & 0.023 \\
\hline $\mathrm{ALT}, \mathrm{U} \cdot \mathrm{L}^{-1}$ & $21.5 \pm 16.1$ & $21.2 \pm 14.2$ & $22.3 \pm 17.4$ & $21.5 \pm 15.5$ & 0.836 \\
\hline \multirow[t]{2}{*}{$\mathrm{AST}, \mathrm{U} \cdot \mathrm{L}^{-1}$} & $21.7 \pm 11.3$ & $22.7 \pm 13.7$ & $21.8 \pm 13.1$ & $22.2 \pm 12.8$ & 0.697 \\
\hline & \multicolumn{3}{|c|}{ Duration of Anti-Infection Treatment } & & 0.791 \\
\hline$\leq 3$ & 28 & 48 & 20 & 96 & 0.765 \\
\hline $4-7$ & 91 & 128 & 55 & 274 & \\
\hline \multirow[t]{2}{*}{$8+$} & 51 & 63 & 35 & 149 & \\
\hline & \multicolumn{2}{|c|}{ Sort of Medicine } & & & $<0.001$ \\
\hline Moxifloxacin & 48 & 66 & 32 & 146 & \\
\hline Levofloxacin & 64 & 130 & 62 & 256 & \\
\hline Ciprofloxacin & 10 & 22 & 8 & 40 & \\
\hline Fleroxacin & 11 & 10 & 4 & 25 & \\
\hline \multirow[t]{2}{*}{ Lomefloxacin } & 37 & 11 & 4 & 52 & \\
\hline & \multicolumn{2}{|c|}{ Site of Infection } & & & $<0.001$ \\
\hline Respiratory System Infection & 57 & 125 & 54 & 236 & \\
\hline Urological System Infection & 19 & 38 & 19 & 80 & \\
\hline Digestive System Infection & 14 & 25 & 19 & 58 & \\
\hline Other Infection & 46 & 22 & 7 & 75 & \\
\hline \multirow[t]{2}{*}{ Mixed Infection } & 34 & 29 & 7 & 70 & \\
\hline & \multicolumn{2}{|c|}{ Gender } & & & 0.186 \\
\hline Male & 98 & 139 & 53 & 290 & \\
\hline \multirow[t]{2}{*}{ Female } & 72 & 100 & 57 & 229 & \\
\hline & \multicolumn{2}{|c|}{ History of Smoking } & & & 0.264 \\
\hline No & 150 & 197 & 92 & 439 & \\
\hline \multirow[t]{2}{*}{ Yes } & 20 & 42 & 18 & 80 & \\
\hline & \multicolumn{2}{|c|}{ History of Drinking } & & & 0.268 \\
\hline No & 162 & 221 & 106 & 489 & \\
\hline Yes & 8 & 18 & 4 & 30 & \\
\hline
\end{tabular}


Table 3. Bivariate correlation analysis.

\begin{tabular}{|c|c|c|c|c|c|c|c|c|c|c|c|c|}
\hline Variables & & Duration & Medication & $\begin{array}{c}\text { Site of } \\
\text { infection }\end{array}$ & Age & Gender & $\begin{array}{c}\text { Smoking } \\
\text { History }\end{array}$ & $\begin{array}{c}\text { Drinking } \\
\text { History }\end{array}$ & $\mathrm{Cr}$ & BUN & ALT & AST \\
\hline \multirow[t]{2}{*}{ Duration } & $\begin{array}{c}\text { Pearson } \\
\text { Correlation }\end{array}$ & 1.000 & -0.081 & -0.030 & $0.091^{*}$ & -0.008 & 0.046 & -0.049 & -0.016 & -0.001 & 0.015 & 0.028 \\
\hline & $\begin{array}{c}\text { Sig. } \\
\text { (2-tailed) }\end{array}$ & & 0.065 & 0.502 & 0.038 & 0.857 & 0.298 & 0.261 & 0.718 & 0.976 & 0.730 & 0.521 \\
\hline \multirow[t]{2}{*}{ Medication } & $\begin{array}{c}\text { Pearson } \\
\text { Correlation }\end{array}$ & -0.081 & 1.000 & $0.396^{* *}$ & $-0.369^{* *}$ & -0.072 & $-0.181^{* *}$ & -0.061 & -0.047 & -0.018 & 0.049 & -0.005 \\
\hline & $\begin{array}{c}\text { Sig. } \\
\text { (2-tailed) }\end{array}$ & 0.065 & & 0.000 & 0.000 & 0.100 & 0.000 & 0.162 & 0.290 & 0.674 & 0.269 & 0.910 \\
\hline $\begin{array}{l}\text { Site of } \\
\text { Infection }\end{array}$ & $\begin{array}{c}\text { Pearson } \\
\text { Correlation }\end{array}$ & -0.030 & $0.396^{* *}$ & 1.000 & $-0.205^{* *}$ & 0.036 & $-0.207^{* *}$ & -0.030 & -0.060 & -0.019 & 0.070 & 0.087 \\
\hline \multirow[t]{2}{*}{ Age } & $\begin{array}{c}\text { Pearson } \\
\text { Correlation }\end{array}$ & $0.091^{*}$ & $-0.369^{* *}$ & $-0.205^{* *}$ & 1.000 & 0.043 & $0.133^{* *}$ & 0.008 & $0.156^{* *}$ & $0.269^{* *}$ & $-0.152^{* *}$ & 0.037 \\
\hline & $\begin{array}{c}\text { Sig. } \\
\text { (2-tailed) }\end{array}$ & 0.038 & 0.000 & 0.000 & & 0.325 & 0.002 & 0.858 & 0.000 & 0.000 & 0.000 & 0.404 \\
\hline \multirow[t]{2}{*}{ Gender } & $\begin{array}{c}\text { Pearson } \\
\text { Correlation }\end{array}$ & -0.008 & -0.072 & 0.036 & 0.043 & 1.000 & $-0.143^{* *}$ & $-0.187^{* *}$ & $-0.306^{* *}$ & $-0.087^{*}$ & $-0.157^{* *}$ & 0.003 \\
\hline & $\begin{array}{c}\text { Sig. } \\
\text { (2-tailed) }\end{array}$ & 0.857 & 0.100 & 0.419 & 0.325 & & 0.001 & 0.000 & 0.000 & 0.047 & 0.000 & 0.949 \\
\hline Smoking History & $\begin{array}{c}\text { Pearson } \\
\text { Correlation }\end{array}$ & 0.046 & $-0.181^{* *}$ & $-0.207^{* *}$ & $0.133^{* *}$ & $-0.143^{* *}$ & 1.000 & $0.489^{* *}$ & -0.040 & 0.046 & -0.008 & 0.012 \\
\hline \multirow{2}{*}{ Drinking History } & $\begin{array}{c}\text { Pearson } \\
\text { Correlation }\end{array}$ & -0.049 & -0.061 & -0.030 & 0.008 & $-0.187^{* *}$ & $0.489^{* *}$ & 1.000 & 0.049 & 0.037 & -0.012 & 0.023 \\
\hline & $\begin{array}{c}\text { Sig. } \\
\text { (2-tailed) }\end{array}$ & 0.261 & 0.162 & 0.488 & 0.858 & 0.000 & 0.000 & & 0.262 & 0.401 & 0.784 & 0.600 \\
\hline \multirow[t]{2}{*}{$\mathrm{Cr}$} & $\begin{array}{c}\text { Pearson } \\
\text { Correlation }\end{array}$ & -0.016 & -0.047 & -0.060 & $0.156^{* *}$ & $-0.306^{* *}$ & -0.040 & 0.049 & 1.000 & $0.582^{* *}$ & 0.020 & -0.001 \\
\hline & $\begin{array}{c}\text { Sig. } \\
\text { (2-tailed) }\end{array}$ & 0.718 & 0.290 & 0.174 & 0.000 & 0.000 & 0.362 & 0.262 & & 0.000 & 0.652 & 0.980 \\
\hline \multirow[t]{2}{*}{ BUN } & $\begin{array}{c}\text { Pearson } \\
\text { Correlation }\end{array}$ & -0.001 & -0.018 & -0.019 & $0.269^{* *}$ & $-0.087^{*}$ & 0.046 & 0.037 & $0.582^{* *}$ & 1.000 & -0.016 & 0.030 \\
\hline & $\begin{array}{c}\text { Sig. } \\
\text { (2-tailed) }\end{array}$ & 0.976 & 0.674 & 0.663 & 0.000 & 0.047 & 0.294 & 0.401 & 0.000 & & 0.719 & 0.491 \\
\hline \multirow[t]{2}{*}{ ALT } & Pearson Correlation & 0.015 & 0.049 & 0.070 & $-0.152^{* *}$ & $-0.157^{* *}$ & -0.008 & -0.012 & 0.020 & -0.016 & 1.000 & $0.629^{* *}$ \\
\hline & $\begin{array}{c}\text { Sig. } \\
\text { (2-tailed) }\end{array}$ & 0.730 & 0.269 & 0.113 & 0.000 & 0.000 & 0.861 & 0.784 & 0.652 & 0.719 & & 0.000 \\
\hline \multirow[t]{2}{*}{$\mathrm{AST}$} & $\begin{array}{c}\text { Pearson } \\
\text { Correlation }\end{array}$ & 0.028 & -0.005 & $0.087^{*}$ & 0.037 & 0.003 & 0.012 & 0.023 & -0.001 & 0.030 & $0.629^{* *}$ & 1.000 \\
\hline & $\begin{array}{c}\text { Sig. } \\
\text { (2-tailed) }\end{array}$ & 0.521 & 0.910 & 0.047 & 0.404 & 0.949 & 0.788 & 0.600 & 0.980 & 0.491 & 0.000 & \\
\hline
\end{tabular}

*Correlation is significant at the 0.05 level (2-tailed). ${ }^{* *}$ Correlation is significant at the 0.01 level (2-tailed). 
clearly exhibited in Figure 1.

\subsection{Factor Analysis}

After ordinal regression, 3 of the 11 variables were significantly associated with the efficacy of the medicine ( $\mathrm{P}$ $<0.05)$. The three factors are age $(\mathrm{OR}=0.979,95 \% \mathrm{CI}$ : $0.969,0.989$ ), variety of medicine (moxifloxacin - OR = 3.465 , 95\% CI: 1.396 , 8.601; levofloxacin - OR $=4.605$, $95 \%$ CI: 1.971, 10.760; ciprofloxacin - OR $=3.220,95 \%$ CI: $1.089,9.552$; compared to lomefloxacin) (levofloxacin - OR $=2.591,95 \%$ CI: $1.130,5.944$; compared to fleroxacin) and site of infection (respiratory system - OR $=3.016,95 \%$ CI: $1.737,5.236$; urological system $-\mathrm{OR}=$ 4.077, 95\% CI: 1.981, 8.391; digestive system - OR = $3.740,95 \%$ CI: $1.849,7.565)$. Although, none of the renal and liver function index was statistically significant, they were still necessary to be focused and continuously discussed. Detailed results see Table 4.

\section{Discussion}

\subsection{Significance of This Research}

Fluoroquinolones are a kind of extensive-spectrum antibiotics, which are effective to both gram-negative and gram-positive bacteria. Over the past 20 years, fluoroquinolones have become one of the fastest growing antimicrobial drugs. Accompanying its popularity, the resistance of bacteria to fluoroquinolones has also increased in recent years. The rational use of antibiotics depends on the following aspects [13]. First, indications of antibiotic medication are necessary in clinical application. If bacterial infection appears to be unlikely, stop the treatment. Second, higher dose and short duration with appropriate selection and route of antibiotics may reduce the incidence of resistance. Third, use pathogen-directed therapy or a shortlist of probable pathogens by culture and sensitivity, and keep up to date with information on antibiotic resistance.

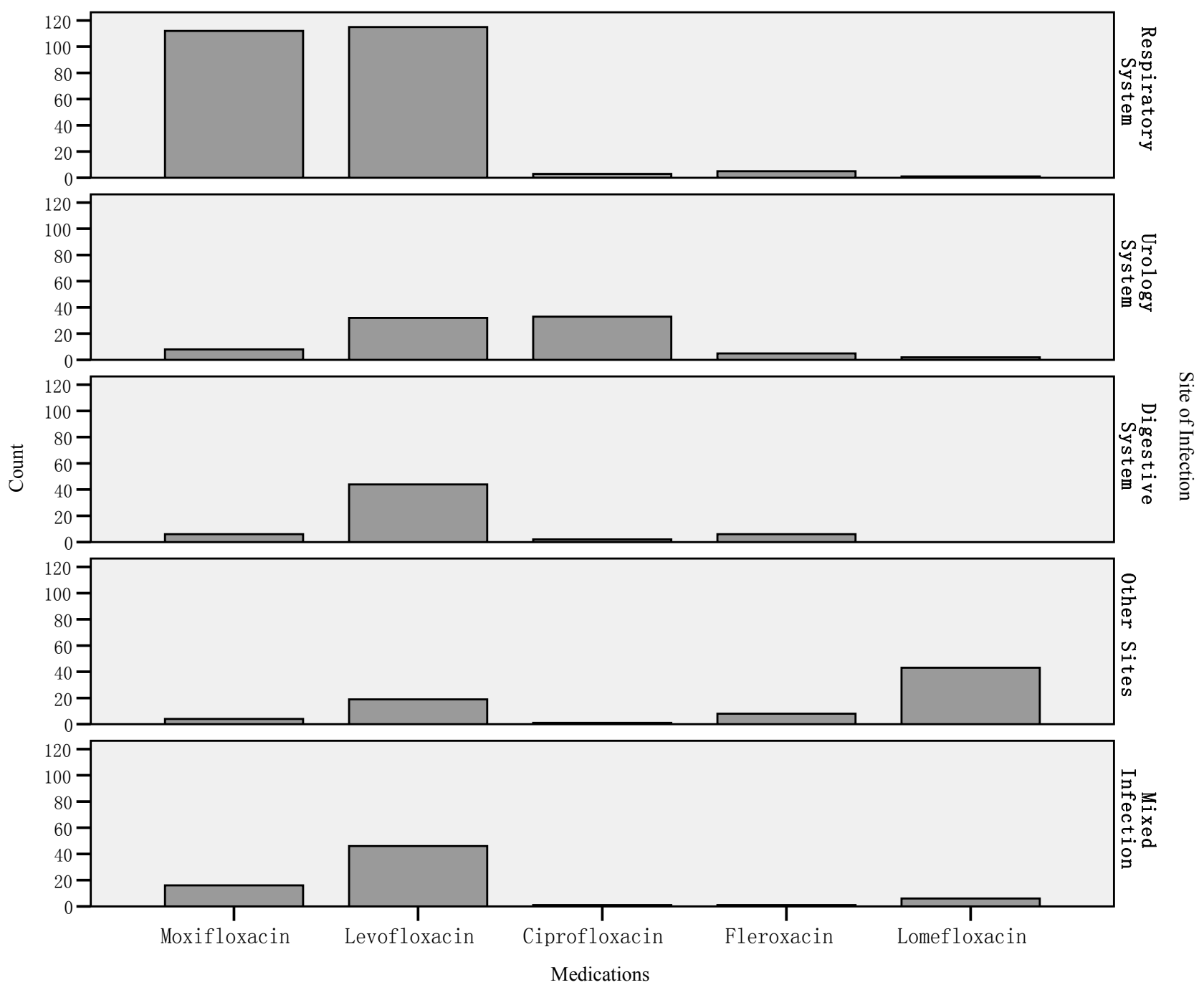

Figure 1. Medications in different cite of infection. 
Table 4. Ordinal regression analysis.

\begin{tabular}{|c|c|c|c|c|c|c|c|}
\hline \multirow{2}{*}{ Variables } & \multirow[b]{2}{*}{ B } & \multirow{2}{*}{ S.E. } & \multirow[b]{2}{*}{ Wald } & \multirow[b]{2}{*}{$P$} & \multirow[b]{2}{*}{ OR } & \multicolumn{2}{|c|}{$95 \% \mathrm{CI}$ for OR } \\
\hline & & & & & & Lower & Upper \\
\hline Age & -0.021 & 0.005 & 16.405 & 0.000 & 0.979 & 0.969 & 0.989 \\
\hline $\mathrm{Cr}$ & 0.004 & 0.005 & 0.634 & 0.426 & 1.004 & 0.995 & 1.013 \\
\hline BUN & -0.059 & 0.047 & 1.603 & 0.206 & 0.943 & 0.861 & 1.033 \\
\hline ALT & -0.004 & 0.007 & 0.255 & 0.613 & 0.996 & 0.982 & 1.011 \\
\hline AST & 0.007 & 0.009 & 0.553 & 0.457 & 1.007 & 0.989 & 1.024 \\
\hline \multicolumn{8}{|c|}{ Duration of Anti-Infection Treatment } \\
\hline$\leq 3$ & 0.130 & 0.259 & 0.254 & 0.615 & 1.139 & 0.686 & 1.892 \\
\hline $4-7$ & -0.003 & 0.201 & 0.000 & 0.988 & 0.997 & 0.672 & 1.479 \\
\hline $8+$ & 0.000 & & & & & & \\
\hline \multicolumn{8}{|l|}{ Sort of Medicine } \\
\hline Moxifloxacin & 1.243 & 0.464 & 7.177 & 0.007 & 3.465 & 1.396 & 8.601 \\
\hline Levofloxacin & 1.527 & 0.433 & 12.439 & 0.000 & 4.605 & 1.971 & 10.760 \\
\hline Ciprofloxacin & 1.169 & 0.553 & 4.467 & 0.035 & 3.220 & 1.089 & 9.522 \\
\hline Fleroxacin & 0.575 & 0.534 & 1.158 & 0.282 & 1.777 & 0.623 & 5.066 \\
\hline Lomefloxacin & 0.000 & & & & & & \\
\hline \multicolumn{8}{|l|}{ Site of Infection } \\
\hline Respiratory System Infection & 1.104 & 0.281 & 15.376 & 0.000 & 3.016 & 1.737 & 5.236 \\
\hline Urological System Infection & 1.405 & 0.368 & 14.559 & 0.000 & 4.077 & 1.981 & 8.391 \\
\hline Digestive System Infection & 1.319 & 0.359 & 13.475 & 0.000 & 3.740 & 1.849 & 7.565 \\
\hline Other Infection & -0.057 & 0.406 & 0.020 & 0.887 & 0.944 & 0.426 & 2.093 \\
\hline Mixed Infection & 0.000 & & & & & & \\
\hline \multicolumn{8}{|l|}{ Gender } \\
\hline Male & -0.355 & 0.193 & 3.393 & 0.065 & 0.701 & 0.481 & 1.023 \\
\hline Female & 0.000 & & & & & & \\
\hline \multicolumn{8}{|l|}{ History of Smoking } \\
\hline No & -0.358 & 0.283 & 1.597 & 0.206 & 0.699 & 0.402 & 1.218 \\
\hline Yes & 0.000 & & & & & & \\
\hline \multicolumn{8}{|l|}{ History of Drinking } \\
\hline No & 0.214 & 0.428 & 0.249 & 0.618 & 1.238 & 0.535 & 2.864 \\
\hline Yes & 0.000 & & & & & & \\
\hline
\end{tabular}

The Ministry of Health of China issued two documents respectively in 2008 and 2009 to regulate the application of antibiotics in the country. Particularly, it was highlighted that the use of fluoroquinolones should be strictly controlled in both empirical therapy and prophylaxis. Nevertheless, most clinical selection of fluoroquinolones was merely on the basis of diagnosis and drug susceptibility test, which ignored the patients' individual conditions. This study investigated the correlation and their inner link between drug efficacy and patients' individual conditions, and assessed the individual factors that affected the efficacy of the drugs so as to provide theory 
basis for drug application.

\subsection{Shortage of This Research}

Although given the concerns above, the most challenging aspect was that the chosen parameters did not include causative organisms. That was because of the lower positive rate $(<20 \%)$ for the detection of causative organisms. We had to abandon this index and choose other possible index to analyze. Moreover, nearly 20 natures of infections belonging to different systems were involved in the paper. While evaluating influential factors, infection position, not the exact nature of infections, were brought into the research. We tried to get the relationship between the therapy result and influential factors to help doctor choose dosage regimen.

\subsection{The Analysis of the Results}

According to the logistic regression analysis, 3 factors contributed to the antimicrobial efficacy of fluoroquinolones. Factors correlated to age, variety of medication and site of infection were significant, but not related to renal and liver functions. In spite of this result, the renal and liver function could manifest its influence through other related factors such as patient age, giving hepatoprotective drug, etc. We would discuss it later.

This study suggested that age factor performed significant influence on the efficacy of fluoroquinolones $(\mathrm{P}<$ 0.05). Noreddin AM, et al. found the pharmacokinetics feature of levofloxacin and gatifloxacin in elderly people whose renal function were poorer, such as varied kidney blood flow and declined glomerular filtration function [14]. Decreased creatinine clearance in elderly patients may lead to an increased drug blood concentration, so that dosage of the drugs needed to be reduced. However, considering the different conditions of elderly patients including history of the disease, age factor could not be regarded as the absolute standards for dosage adjustment. Related research showed pharmacokinetic parameters of ciprofloxacin were slightly different in subjects with different age divided according the standards with 65 years older [15]. According to the results of our study, the efficacy of fluoroquinolones achieved better efficacy in younger people, mean age of cured population was 53.9, which may also attribute to their shorter case history, better physical condition, less complications. Therefore, special attentions should be paid when fluoroquinolones were applied to elderly patients.

The detailed data involved the kinds of fluoroquinolones and sites of infection were described above. In correlation analysis, variety of medicine was statistically associated with sites of infection $(\mathrm{P}<0.05)$. The results of ordinal logistic regression analysis showed both the two factors influence the therapeutic effects. More than
$65 \%$ patients treated by moxifloxacin, levofloxacin and ciprofloxacin were effective (improved or recovered); only less than $30 \%$ of lomefloxacin were effective. It was statistically significant that moxifloxacin and levofloxacin were more effective than lomefloxacin. After analyzing the correlation of the two factors, we found that moxifloxacin were principally used in respiratory infection and lomefloxacin were for other infection from Burn and Plastic Surgery Dept. One study by Thabet L et al. [16] illustrated that fluoroquinolones usage was associated with resistance in both pathogens $S$. aureus and $P$. aeruginosa, and could be a risk factor for colonization and infection in an intensive care burn unit. It was demonstrated that fluoroquinolones were more effective in respiratory system, urological system, and digestion system. These kinds of usage were recommended.

Creatinine is small molecule produced from human body muscle tissue metabolism, mainly excreted by glomerular filtration. Under normal circumstances, $\mathrm{Cr}$ value shall be maintained within a certain range. Creatinine clearance ratio (CLcr) calculated from $\mathrm{Cr}$ value, reflects the excreting ability of kidney. The lower CLcr is, the lower kidney's excretion function is.

Pharmacokinetic data from single-dose studies on healthy volunteers revealed the rule of the commonly used fluoroquinolones: levofloxacin was most dependent on renal excretion, followed by gatifloxacin, ofloxacin and gemifloxacin, while ciprofloxacin and moxifloxacin were the least dependent [17]. Since levofloxacin and gatifloxacin were principally excreted by kidney, clearance decreased and half-life increased for both of the two drugs, as the degree of renal insufficiency increased. Jing Zhang, et al. reported that the blood concentration of levofloxacin elevated in renal impaired patients as the half-life prolonged, due to the change of creatinine clearance [18]. Bellmann et al.'s research on severe renal dysfunction patients showed the half life of levofloxacin is $20-25 \mathrm{~h}$, which was 3 times of value in healthy volunteers (7 h) [19]. Ciprofloxacin was eliminated by renal and extra-renal routes; therefore, drug accumulation did not occur until renal function was severely impaired (creatinine clearance $<20-30 \mathrm{ml} / \mathrm{min}$ ) [20]. The dosage of moxifloxacin did not need to be adjusted in renal dysfunction patients, because the drug was mainly eliminated through nonrenal routes [21]. It was recommended that dosage should be adjusted according to the degree of renal damage which was classified into three levels: mild, moderate or severe, by creatinine clearance, due to the correlation between kidney filtration function and drug elimination rate [22]. Special attention should be given to patients with severe renal dysfunction. It was necessary to determine drug blood concentration and monitor kidney function, and then design individualized therapeutic regimen to look forward to get the best therapeutic effect 
and the least adverse drug reactions (ADRs) related to protect kidney and other organs. In addition, it was better to select a regimen getting renal toxicity as lower as possible. Although the association between renal function and efficacy in logistic regression was not statistically significant, there were differences among the three groups through $\chi^{2}$ analysis in this paper. The correlation analysis showed significant correlation between age and renal function index. Therefore, more attentions should be paid to elderly patients, who probably had decreased renal functions.

ALT, AST are a kind of aminotransferase, existing in liver cells. Elevated ALT, AST concentrations in the plasma can reflect the change of liver function. In patients with mildly to moderately impaired hepatic function, moxifloxacin exposure was approximately $23 \%$ higher than that in healthy volunteers [21]. Like moxifloxacin, sparfloxacin was principally eliminated by nonrenal pathway [23]. For ciprofloxacin, one third of a dose was eliminated by nonrenal mechanisms [24], while no significant change in the pharmacokinetics would be expected for levofloxacin in liver dysfunction patients, since these drugs were mainly cleared by kidney [25]. ALT, AST values were not statistically significant in ordinal regression, but changes in hepatic function could potentially affect the metabolism of fluoroquinolones, resulting in increased drug concentrations, especially those agents with significant nonrenal clearance mechanisms. The results suggested that different efficacy of fluoroquinolones in patients with liver damage may be related to the alternation of drug metabolisms and drug blood concentrations. Literature suggested that dosage adjustments for moxifloxacin, ciprofloxacin and garifloxacin were not necessary in patients with hepatic dysfunction [21,26,27]. Although liver toxicity of fluoroquinolones was relatively lower, there were also cases reported on serious liver toxicity [28,29]. Thus, patients with liver disease should select appropriate therapeutic regimen when applying fluoroquinolones so as to increase its safety.

\section{Conclusion}

Age, a variety of medicine and sites of infection were the influential factors of efficacy of fluoroquinolones in anti-infective treatment. FQNS were more effective in young population with bacterial infection. That may attribute to their shorter case history, better physical conditions, and fewer complications. For the older population treated with FQNS, renal or hepatic dysfunction should be monitored because of their potentially changed drug blood concentrations. From the infection population conformed as the indication of FQNS, the efficacy of levofloxacin was absolutely better than that of fleroxacin and lomefloxacin, and the efficacy of moxifloxacin and ciprofloxacin was superior to that of lomefloxacin, while this would be correlated to site of infection. Fluoroquinolones could be recommended to be applied in respiratory system, urological system, and digestion system infection, other than in burn patients.

\section{Acknowledgements}

This work has been supported by the science and technology project (project number 13KG108) of the Public Health Bureau, Tianjin, China.

\section{REFERENCES}

[1] G. Y. Lesher, E. J. Froelich, M. D. Gruett, J. H. Bailey and R. P. Brundage, "1,8-Naphthyridine Derivatives: A New Class of Chemotherapeutic Agents," Journal of Medicinal and Pharmaceutical Chemistry, Vol. 5, No. 5, 1962, pp. 1063-1065. http://dx.doi.org/10.1021/jm01240a021

[2] H. Koga, A. Itoh, S. Murayama, S. Suzue and T. Irikura, "Structure-Activity Relation-Ships of Antibacterial 6,7and 7,8-Disubstituted 1-Alkyl-1,4-dihydro-4-oxoquinoline-3-carboxylic Acids," Journal of Medicinal Chemistry, Vol. 23, No. 12, 1980, pp. 1358-1363.

http://dx.doi.org/10.1021/jm00186a014

[3] H. C. Neu, "Clinical Use of the Quinolones," Lancet, Vol. 330, No. 8571, 1987, pp. 1319-1322. http://dx.doi.org/10.1016/S0140-6736(87)91205-0

[4] L. A. Mitscher, "Bacterial Topoisomerase Inhibitors: Quinolone and Pyridone Antibacterial Agents," Chemical Reviews, Vol. 105, No. 2, 2005, pp. 559-592. http://dx.doi.org/10.1021/cr030101q

[5] H. J. Adam, D. J. Hoban, A. S. Gin and G. G. Zhanel, "Association between Fluoroquinolone Usage and a Dramatic Rise in Ciprofloxacin-Resistant Streptococcus pneumoniae in Canada, 1997-2006," International Journal of Antimicrobial Agents, Vol. 34, No. 1, 2009, pp. 82-85.

http://dx.doi.org/10.1016/j.ijantimicag.2009.02.002

[6] D. Yanagi, G. C. de Vries, D. Rahardjo, L. Alimsardjono, E. B. Wasito, I. De, et al., "Emergence of Fluoroquinolone-Resistant Strains of Salmonella enterica in Surabaya, Indonesia," Diagnostic Microbiology and Infectious Disease, Vol. 64, No. 4, 2009, pp. 422-426. http://dx.doi.org/10.1016/j.diagmicrobio.2009.04.006

[7] M. Mac Aogáin, M. J. Mooij, C. Adams, J. Clair and F. O'Gara, "Emergence of Extended-Spectrum $\beta$-Lactamase and Fluoroquinolone Resistance Genes among Irish Multidrug-Resistant Isolates," Diagnostic Microbiology and Infectious Disease, Vol. 67, No. 1, 2010, pp. 106-109. http://dx.doi.org/10.1016/j.diagmicrobio.2009.12.017

[8] C. M. Chang, T. L. Lauderdale, H. C. Lee, N. Y. Lee, C. J. $\mathrm{Wu}, \mathrm{P}$. L. Chen, et al., "Colonisation of FluoroquinoloneResistant Haemophilus influenzae among Nursing Home Residents in Southern Taiwan," Journal of Hospital Infection, Vol. 75, No. 4, 2010, pp. 304-308. http://dx.doi.org/10.1016/j.jhin.2009.12.020

[9] S. Jazayeri, M. H. Moshafi, L. Firoozpour, S. Emami, S. Rajabalian, M. Haddad, et al., "Synthesis and Antibacte- 
rial Activity of Nitroaryl Thiadiazole-Gatifloxacin Hybrids," European Journal of Medicinal Chemistry, Vol. 44, No. 3, 2009, pp. 1205-1209. http://dx.doi.org/10.1016/j.ejmech.2008.09.012

[10] S. Lemaire, F. Van Bambeke and P. M. Tulkens, "Activity of Finafloxacin, a Novel Fluoroquinolone with Increased Activity at Acid $\mathrm{pH}$, towards Extracellular and Intracellular Staphylococcus aureus, Listeria monocytogenes and Legionella pneumophila," International Journal of Antimicrobial Agents, Vol. 38, No. 1, 2011, pp. 5259. http://dx.doi.org/10.1016/j.ijantimicag.2011.03.002

[11] D. S. Billal, M. Hotomi, S. S. Yan, D. P. Fedorko, J. Shimada, K. Fujihara, et al., "Loss of Erythromycin Resistance Genes from Strains of Streptococcus pyogenes That Have Developed Resistance to Levofloxacin," Diagnostic Microbiology and Infectious Disease, Vol. 64, No. 2, 2009, pp. 225-228. http://dx.doi.org/10.1016/i.diagmicrobio.2009.01.034

[12] D. H. Zhao, Y. J. Li, S. M. Xie, M. Zhao and J. B. Yang, "Consideration for Clinical Efficacy Evaluation Criterion in Guidance for Clinical Trials of Antibacterial Agents in China," Clinical Pharmacology \& Therapeutics, Vol. 24, No. 6, 2008, pp. 564-565.

[13] H. M. Lode, "Rational Antibiotic Therapy and the Position of Ampicillin/Sulbactam," Antimicrobial Agents, Vol. 32, No. 1, 2008, pp. 10-28. http://dx.doi.org/10.1016/j.ijantimicag.2008.02.004

[14] A. M. Noreddin, D. J. Hoban and G. G. Zhanel, "Comparison of Gatifloxacin and Levofloxacin Administered at Various Dosing Regimens to Hospitalised Patients with Community-Acquired Pneumonia: Pharmacodynamic Target Attainment Study Using North American Surveillance Data for Streptococcus pneumoniae," International Journal of Antimicrobial Agents, Vol. 26, No. 2, 2005, pp. 120125. http://dx.doi.org/10.1016/j.ijantimicag.2005.04.012

[15] L. R. Wiseman and J. A. Balfour, "Ciprofloxacin. A Review of Its Pharmacological Profile and Therapeutic Use in the Elderly," Drugs \& Aging, Vol. 4, No. 2, 1994, pp. 145-173. http://dx.doi.org/10.2165/00002512-199404020-00007

[16] L. Thabet, M. Memmi, A. Turki and A. A. Messadi, "The Impact of Fluoroquinolones Use on Antibiotic Resistance in an Intensive Care Burn Department," La Tunisie Médicale, Vol. 88, No. 10, 2010, pp. 696-699.

[17] H. Lode and M. Allewelt, "Role of Newer Fluoroquinolones in Lower Respiratory Tract Infections," Journal of Antimicrobial Chemotherapy, Vol. 49, No. 5, 2002, pp. 709-712. http://dx.doi.org/10.1093/jac/dkf024

[18] J. Zhang, J. F. Xu, Y. B. Liu, Z. K. Xiao, J. A. Huang, B. $\mathrm{Si}$, et al., "Population Pharmacokinetics of Oral Levofloxacin $500 \mathrm{mg}$ Once-Daily Dosage in Community-Acquired Lower Respiratory Tract Infections: Results of a Prospective Multicenter Study in China," Journal of Infection and Chemotherapy, Vol. 15, No. 5, 2009, pp. 293-300. http://dx.doi.org/10.1007/s10156-009-0714-8

[19] R. Bellmann, P. Egger, W. Gritsch, R. Bellmann-Weiler, M. Joannidis, S. Dunzendorfer, et al., "Elimination of
Levofloxacin in Critically Ill Patients with Renal Failure: Influence of Continuous Veno-Venous Hemofiltration," International Journal of Clinical Pharmacology and Therapeutics, Vol. 40, No. 4, 2002, pp. 142-149.

[20] A. Forrest, M. Weir, K. I. Plaisance, G. L. Drusano, J. Leslie and H. C. Standiford, "Relationships between Renal Function and Disposition of Ciprofloxacin," Antimicrobial Agents and Chemotherapy, Vol. 32, No. 10, 1988, pp. 1537-1540.

http://dx.doi.org/10.1128/AAC.32.10.1537

[21] H. Stass and J. Lettieri, "Pharmacokinetics of Moxifloxacin in Special Populations," Drugs, Vol. 58, Suppl. 2, 1999, pp. 233-234.

http://dx.doi.org/10.2165/00003495-199958002-00072

[22] H. Ohtani, Y. Kinoshita, Y. Nagasaki, et al., "Dosage Adjustment of Quinolone Antibiotics and AngiotensinConverting Enzyme Inhibitors in Patients with Renal Dysfunction," International Journal of Clinical Pharmacology and Therapeutics, Vol. 44, No. 9, 2006, pp. 428-437. http://dx.doi.org/10.5414/CPP44428

[23] P. Mugnier, A. Taburet, P. Wyld, et al., "Pharmacokinetics of Sparfloxacin in Patients with Hepatic Failure," 34th Interscience Conference on Antimicrobial Agents and Chemotherapy, Orlando, 4 October 1994

[24] G. L. Drusano, M. Weir, A. Forrest, K. Plaisance, T. Emm and H. C. Standiford, "Pharmacokinetics of Intravenously Administered Ciprofloxacin in Patients with Various Degrees of Renal Function," Antimicrobial Agents and Chemotherapy, Vol. 31, No. 6, 1987, pp. 860-864.

http://dx.doi.org/10.1128/AAC.31.6.860

[25] L. G. Gisclon, C. R. Curtin, R. R. Williams, et al., "The Pharmacokinetics of Levofloxacin in Subjects with Renal Impairment, and in Subjects Receiving Hemodialysis or Continuous Ambulatory Peritoneal Dialysis," Program and Abstracts of the 36th Interscience Conference on Antimicrobial Agents and Chemotherapy, New Orleans, 1518 September 1996, Abstract A13.

[26] K. Vance-Bryan, D. Guay and J. Rotschafer, "Clinical Pharmacokinet-Ics of Ciprofloxacin," Clinical Pharmacokinetics, Vol. 19, No. 6, 1990, pp. 434-461. http://dx.doi.org/10.2165/00003088-199019060-00003

[27] D. M. Grasela, B. Christofalo, G. D. Kollia, G. Duncan, R. Noveck, J. A. Manning, Jr., et al., "Safety and Pharmacokinetics of a Single Oral Dose of Gatifloxacin in Patients with Moderate to Severe Hepatic Impairment," Pharmacotherapy, Vol. 20, No. 6, 2000, pp. 87S-94S. http://dx.doi.org/10.1592/phco.20.8.87S.35187

[28] J. Figueira-Coelho, O. Pereira, B. Picado, P. Mendonça, J. Neves-Costa and J. Neta, "Acute Hepatitis Associated with the Use of Levofloxacin," Clinical Therapeutics, Vol. 32, No. 10, 2010, pp. 1733-1737. http://dx.doi.org/10.1016/j.clinthera.2010.09.004

[29] R. Verma, R. Dhamija, D. H. Batts, S. C. Ross and M. E. Loehrke, "Moxifloxacin Induced Fatal Hepatotoxicity in a 72-Year-Old Man: A Case Report," Cases Journal, Vol. 2, 2009, p. 8063 . http://dx.doi.org/10.4076/1757-1626-2-8063 